\title{
Drill-specific head impact exposure in youth football practice
}

\author{
Eamon T. Campolettano, BS, Steven Rowson, PhD, and Stefan M. Duma, PhD \\ Department of Biomedical Engineering and Mechanics, Virginia Tech, Blacksburg, Virginia
}

OBJECTIVE Although 70\% of football players in the United States are youth players (6-14 years old), most research on head impacts in football has focused on high school, collegiate, or professional populations. The objective of this study was to identify the specific activities associated with high-magnitude (acceleration $>40 \mathrm{~g}$ ) head impacts in youth football practices.

METHODS A total of 34 players (mean age $9.9 \pm 0.6$ years) on 2 youth teams were equipped with helmet-mounted accelerometer arrays that recorded head accelerations associated with impacts in practices and games. Videos of practices and games were used to verify all head impacts and identify specific drills associated with each head impact.

RESULTS A total of 6813 impacts were recorded, of which 408 had accelerations exceeding $40 \mathrm{~g}(6.0 \%)$. For each type of practice drill, impact rates were computed that accounted for the length of time that teams spent on each drill. The tackling drill King of the Circle had the highest impact rate $(95 \% \mathrm{Cl} 25.6-68.3$ impacts/hr). Impact rates for tackling drills (those conducted without a blocker [95\% Cl 14.7-21.9 impacts/hr] and those with a blocker [95\% Cl 10.5-23.1 impacts/ $\mathrm{hr}]$ ) did not differ from game impact rates $(95 \% \mathrm{Cl} 14.2-21.6$ impacts/hr). Tackling drills were observed to have a greater proportion (between $40 \%$ and $50 \%$ ) of impacts exceeding $60 \mathrm{~g}$ than games (25\%). The teams in this study participated in tackling or blocking drills for only $22 \%$ of their overall practice times, but these drills were responsible for $86 \%$ of all practice impacts exceeding $40 \mathrm{~g}$.

CONCLUSIONS In youth football, high-magnitude impacts occur more often in practices than games, and some practice drills are associated with higher impact rates and accelerations than others. To mitigate high-magnitude head impact exposure in youth football, practices should be modified to decrease the time spent in drills with high impact rates, potentially eliminating a drill such as King of the Circle altogether.

http://thejns.org/doi/abs/10.3171/2016.5.PEDS1696

KEY WORDS concussion; biomechanics; linear; rotational; acceleration; pediatrics; trauma

$I^{1}$ $\mathrm{T}$ is estimated that between 1.6 and 3.8 million sportsrelated concussions occur in the United States each year. ${ }^{6}, 16$ Sports-related concussions have been the subject of much public attention due to research suggesting potential long-term effects resulting from these brain injuries. ${ }^{25}$ Football has been linked to the highest incidence of brain injury among team sports, spurring a great deal of biomechanics research related to concussions and football. ${ }^{3-6,11,16,19,20,22,23}$ The prevailing thought for concussion mitigation in football today is to limit exposure to head impacts through proper teaching and rule modification. ${ }^{10}$

Head impact biomechanics research for football has largely relied on outfitting athletes with helmet instrumentation during play to collect head impact data. This research has resulted in data on millions of head impacts, which have been used to quantify tolerance to concussion and characterize head impact exposure in football. ${ }^{15}$ Most research on head impact exposure in football has focused on high school, collegiate, and professional populations, despite the fact that $70 \%$ of all football players in the United States are youth players (6-14 years old).${ }^{13}$ Recently, researchers have begun to use instrumentation such as helmet-mounted accelerometer arrays to collect data on youth football players to quantify head impact exposure and assess concussion tolerance., $, 13,14,27$ Daniel et al. provided 7 players (7-8 years old) with helmets equipped with instrumentation to measure head impacts. With the use of these helmets, Daniel et. al demonstrated that more highmagnitude impacts occurred in practice than in games. ${ }^{13}$ The findings from that study were part of the process that ultimately led to rule changes in the Pop Warner youth sports organization that were aimed at mitigating head

ABBREVIATIONS HIT = Head Impact Telemetry.

SUBMITTED February 17, 2016. ACCEPTED May 4, 2016.

INCLUDE WHEN CITING Published online August 23, 2016; DOI: 10.3171/2016.5.PEDS1696. 
impact exposure in youth football. ${ }^{21}$ The following year, Cobb et al. followed 3 youth football teams with players 9-12 years of age and found that teams adhering to the policy changes experienced a $40 \%$ reduction in overall impacts relative to those that did not. ${ }^{7}$ Due to differences in age, head impact magnitude and frequency were found to be greater in the study by Cobb et al. than in the study by Daniel et al., although both magnitude and frequency were still less than that found in older populations..$^{12,26}$

While these studies provided valuable insight regarding head impact exposure in youth football players, they investigated practices and games as a whole, with little analysis quantifying the causation of high-magnitude impacts, which are associated with higher risks of head injury. The objective of this study was to analyze youth football practices and determine which drills were associated with the highest magnitude impacts. Secondarily, this study aimed to determine how representative practice drills were of games by comparing impact rates between practices and games. This analysis represents a first step toward developing pointed efforts to improve player safety in youth football. Conducted on a larger scale, these methods and the resulting data could be used to inform further policy changes to mitigate head impact exposure in youth football.

\section{Methods}

Two youth football teams composed of 9- to 11-yearold players were included in this study, which was approved by the Virginia Tech Institutional Review Board. Guardians provided written consent, and the youth players verbally assented to participation. A total of 34 players were recruited and chose to participate. Each received a helmet instrumented with accelerometer arrays (Head Impact Telemetry [HIT] System, Simbex). Study participants had a mean age of $9.9 \pm 0.6$ years and a mean body mass of $37.4 \pm 9.6 \mathrm{~kg}$. Between the 2 teams, data collection comprised a total of 65 sessions, of which 55 were practices and 10 were games.

The HIT System consists of a 6-accelerometer array that is mounted inside of Riddell Revolution or Speed helmets. A $10 \mathrm{~g}$ resultant acceleration threshold was used to distinguish between actual impacts and accelerations levels that could be attained by simply jumping or running quickly.

The accelerometers are spring mounted so that contact with the head is maintained for the duration of impact. This ensures measurement of head acceleration, rather than helmet acceleration. ${ }^{17}$ Players wore the instrumented helmets at each practice and game throughout the season. Helmet instrumentation collected data continuously, but when an individual data channel exceeded the $14.4 \mathrm{~g}$ threshold, data acquisition was automatically triggered, capturing $40 \mathrm{msec}$ of data, including $8 \mathrm{msec}$ of preimpact data. Impact data were then wirelessly transmitted from the helmets to a sideline computer, in which linear and rotational accelerations were computed.$^{8,23}$

Games and practices were filmed to facilitate video verification of head impacts. For every impact greater than or equal to $40 \mathrm{~g}$ in practice, video was also used to identify the specific drill/activity associated with impact. Each of these impacts was assigned to one of 9 practice drill classifications (Table 1). Game impacts exceeding $40 \mathrm{~g}$ were also verified to allow for comparison of high-magnitude head impact rates between practices and games.

Investigating practices at the drill level required determination of numbers of impacts and time spent for each drill type. Practice videos and activity logs kept for each day of practice were used to determine the total time spent participating in each drill type. Both the number of impacts and time spent in a drill varied greatly over the course of the season, necessitating the use of a normalized impact rate for comparisons to be made. Impact rates for each drill were computed on a per-hour basis to characterize each drill type. Byar's method, which represents an exact approximation to the Poisson distribution and retains high levels of accuracy for both small and large counts, was used to compute $95 \%$ confidence intervals for the impact rates in this study. ${ }^{2}$ Boxplots were developed for each drill type for both linear and rotational resultant acceleration. The first and third quartiles enclose the box, with any data points beyond 1.5 times the interquartile range from the first or third quartile defined as outliers. ${ }^{18}$ The corresponding impact rates and boxplots were also calculated for games to provide a means of comparison.

\section{Results}

For the season, a total of 6813 impacts were recorded and verified from instrumented players, of which 408 had accelerations exceeding $40 \mathrm{~g}$. These impacts were video verified, with $314(77 \%)$ occurring in practice and the remaining $94(23 \%)$ in games. Of 6813 overall season impacts, $408(6.0 \%)$ total impacts exceeded $40 \mathrm{~g}, 118(1.7 \%)$ exceeded $60 \mathrm{~g}$, and $59(0.9 \%)$ exceeded $70 \mathrm{~g}$. Although assessment of player injury was deferred to usual league protocol in instances of suspected concussion, no players in the study sustained a clinically diagnosed concussion.

The greatest number of impacts exceeding $40 \mathrm{~g}$ occurred in tackling drills, even though they were practiced only half as often as organized offensive or defensive drills (Table 2). A $40 \mathrm{~g}$ acceleration value was selected as the

TABLE 1. Practice drills associated with $>40 \mathrm{~g}$ impacts

\begin{tabular}{|c|c|}
\hline Drill Type* & Description \\
\hline Blocking drill & Drills focused on teaching blocking \\
\hline Tackling drill-Blocker & $\begin{array}{l}\text { At least } 1 \text { blocker present as well as a ball } \\
\text { carrier \& tackler }\end{array}$ \\
\hline $\begin{array}{l}\text { Tackling drill-No } \\
\text { Blocker }\end{array}$ & Only a ball carrier \& tackler participate \\
\hline King of the Circle & $\begin{array}{l}\text { Tackling drill: player in middle of circle } \\
\text { rushes at player on perimeter of circle }\end{array}$ \\
\hline Scrimmage & Full 11 vs 11 offense vs defense \\
\hline Offense vs Defense & $\begin{array}{l}\text { Small-scale (5 vs } 5 \text { up to } 8 \text { vs } 8 \text { ) offense vs } \\
\text { defense }\end{array}$ \\
\hline Offense or Defense & $\begin{array}{l}11 \text { offensive or defensive players w/ 3-4 } \\
\text { proxy players on the other side }\end{array}$ \\
\hline Passing or running drills & Pass catching or rushing drills \\
\hline Other & All other practice activities \\
\hline
\end{tabular}

* Most drills, even those not designated as tackling drills, resulted in tackling. 
TABLE 2. Practice drill frequency and severity*

\begin{tabular}{lcrrrrr}
\hline \multirow{2}{*}{ Drill Type } & $\begin{array}{c}\text { Time Spent in Drill } \\
\text { (hrs/season) } \dagger\end{array}$ & \multicolumn{5}{c}{ Impact Severity (no. of impacts) } \\
\cline { 3 - 7 } & & $>40 \mathrm{~g}$ & $>50 \mathrm{~g}$ & $>60 \mathrm{~g}$ & $>70 \mathrm{~g}$ & $>80 \mathrm{~g}$ \\
\hline Tackling & 5.767 & 104 & 65 & 38 & 21 & 7 \\
\hline Tackling drill-No Blocker & 1.700 & 27 & 19 & 14 & 7 & 2 \\
\hline Tackling drill-Blocker & 0.417 & 18 & 10 & 4 & 0 & 0 \\
\hline King of the Circle & 5.833 & 86 & 48 & 21 & 11 & 7 \\
\hline Offense vs Defense & & & & & & \\
\hline Skill & 4.817 & 34 & 16 & 3 & 2 & 1 \\
\hline Blocking drill & 1.250 & 11 & 5 & 3 & 0 & 0 \\
\hline Scrimmage & 15.800 & 12 & 6 & 4 & 0 & 0 \\
\hline Offense or Defense & 3.783 & 14 & 9 & 2 & 1 & 1 \\
\hline Running or passing & 0.850 & 8 & 6 & 6 & 3 & 3 \\
\hline Other & 5.333 & 94 & 40 & 23 & 14 & 6 \\
\hline Games & & & & & \\
\hline
\end{tabular}

* Impact frequency decreases with increasing impact severity for all drill types. Drills resulting in tackling produced more high-magnitude impacts than those that do not.

$\dagger$ Most time was devoted to drills that most closely replicate a game environment.

threshold for high-magnitude impacts which included the top $6 \%$ of impacts that players in this study experienced, while the $60 \mathrm{~g}$ threshold included the top $2 \%$ of impacts and is within the range of previously measured concussive impacts in this population (concussions at the youth level have been reported at $58 \mathrm{~g}$ and $64 \mathrm{~g}$ ). ${ }^{7}$ Drills involving tackling resulted in a higher rate of impacts than those that did not (Fig. 1). Increasing severity thresholds resulted in lower rates of impact across all drills. Overall, impact rates for games (95\% CI 14.2-21.6 impacts/hr) did not vary greatly from those for tackling practice drills (those conducted without a blocker [95\% CI 14.7-21.9 impacts/hr] and those with a blocker [95\% CI 10.5-23.1 impacts/hr]), with the exception of King of the Circle, which had the highest impact rate (95\% CI 25.6-68.3 impacts/hr). This trend was consistent for all acceleration severity thresholds.
Distributions of both linear and rotational acceleration magnitudes varied between drill types and games (Fig. 2). Tackling drills were associated with head impacts of greater severity than nontackling drills. Furthermore, the proportion of impacts greater than $60 \mathrm{~g}$ was higher in tackling drills (between $40 \%$ and $50 \%$ ) than in games (25\%). Similar trends were observed for rotational acceleration, with tackling drills being associated with a greater proportion of high-magnitude accelerations than nontackling drills or games.

\section{Discussion}

Previous work on youth football head impact exposure has investigated magnitude and frequency of impacts but has yet to explore the specific causation of high-magnitude

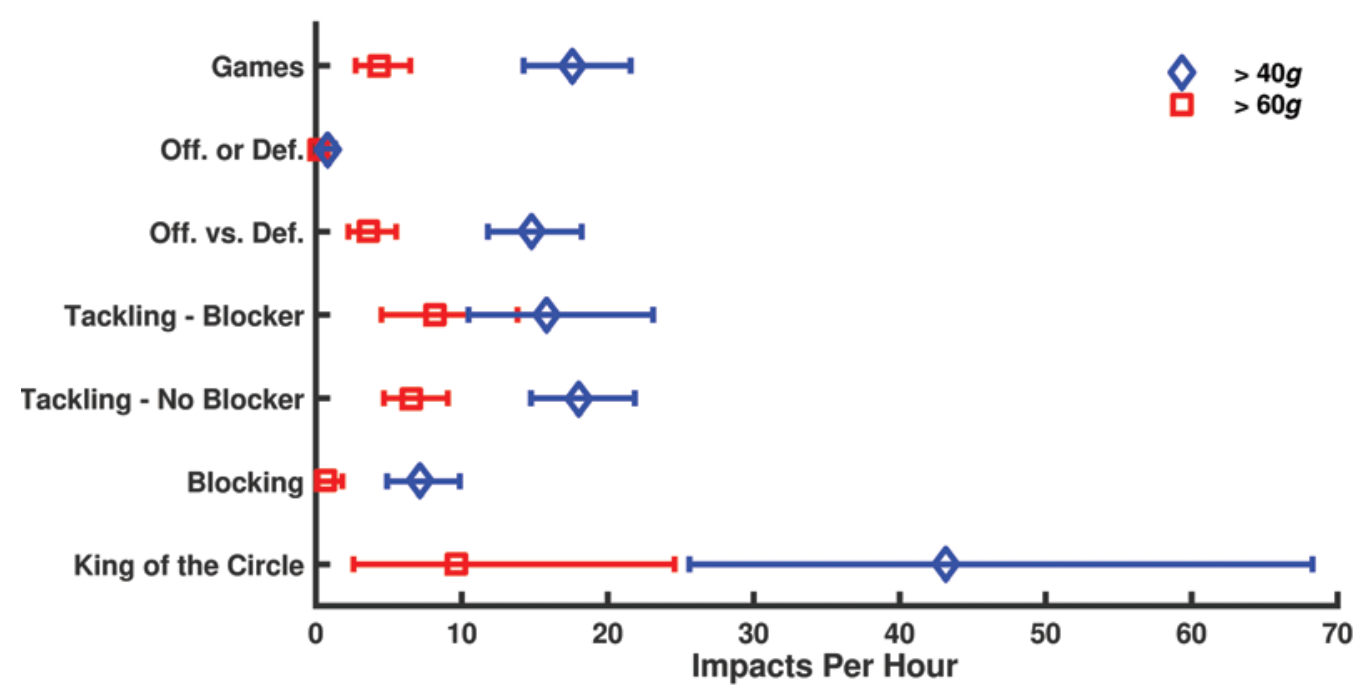

FIG. 1. King of the Circle led to the highest impact rate of all practice drills (25.6-68.3 impacts/hr). Drills resulting in a tackle were found to lead to higher impact rates. Symbols represent the mean and bars represent the $95 \%$ Cls. Def. = defense; Off. = offense. Figure is available in color online only. 

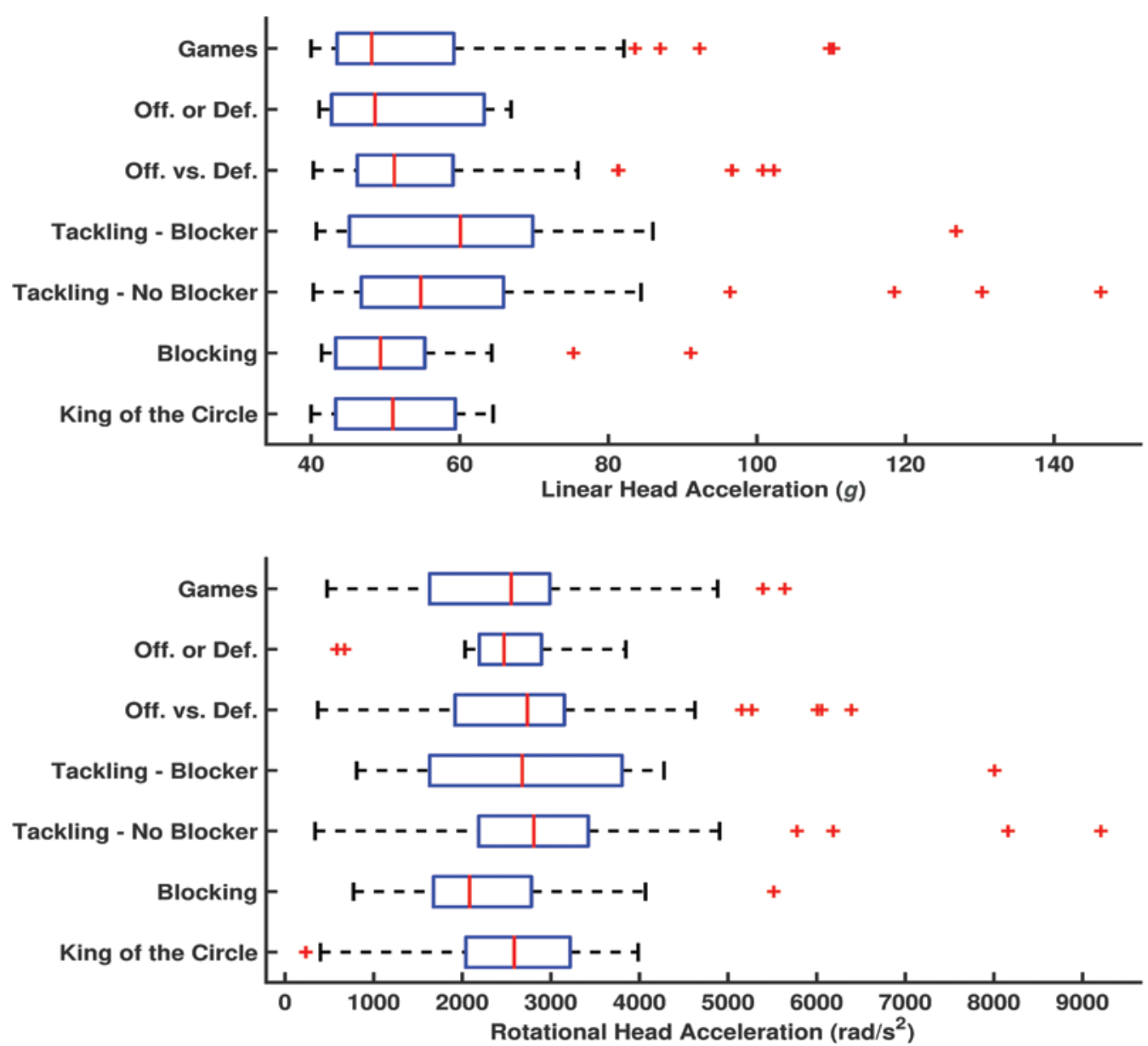

FIG. 2. Tackling drills were found to have the largest proportion of impacts over $70 \mathrm{~g}$. Tackling drills were associated with a greater acceleration severity than games. Tackling drills comprised Tackling-Blocker, Tackling-No Blocker, King of the Circle, and Offense vs Defense. All other drills were considered skill drills. Only impacts exceeding $40 \mathrm{~g}$ were included. The red line in each box denotes the median; boxes, the interquartile range; and plus signs, the outliers. The whiskers represent the threshold for defining a point as being within the data set or being an outlier. They are defined to be 1.5 times the interquartile range from the first or third quartile. If an outlier did not exist for a particular drill, then they represent the minimum and maximum in that scenario. Figure is available in color online only.

head impacts., $73,14,27$ The proportion of high-magnitude head impacts (those exceeding $40 \mathrm{~g}$ ) in youth practices (77\%) was similar to the $79 \%$ found by Daniel et al. ${ }^{13}$ Furthermore, the proportion of high-magnitude impacts for severity thresholds of $40 \mathrm{~g}$ and $60 \mathrm{~g}$ was consistent with that observed by Cobb et al. ${ }^{7}$ This relationship between high-magnitude impacts in practices and games contrasts with that observed in high school and collegiate football, where high-magnitude impacts were more often observed in games than in practices ${ }^{4,9,10,24}$ Efforts aimed at reducing high-magnitude impacts in practices necessitate an evaluation of practice drill structure.

Impact rate differed markedly between practice drills with and without tackling for all acceleration severity levels. Impacts without tackling resulted in fewer than $10 \mathrm{im}-$ pacts above $40 \mathrm{~g}$ per practice-hour, while drills involving tackling exceeded this by at least a factor of 2 . King of the Circle produced high-magnitude impacts more frequently than any other activity because of the speed at which it is performed (Fig. 1). A ball carrier in the middle of a circle rushes at 3 different defenders on the perimeter of the circle. When the ball carrier rushes at each defender on the perimeter, he must be tackled. The drill continues until each player has had the opportunity to be the ball carrier. Notably, this drill was carried out for the shortest amount of time of all drills assessed. Furthermore, no impact from King of the Circle exceeded $70 g$ (Table 2). Tackling drills, with or without blockers, were associated with the highest proportion of impacts over $70 \mathrm{~g}$. The presence of a blocker did not have an effect on the impact rate. This suggests that the end goal of tackling has more bearing on the high-magnitude impact rate than does the drill environment itself. Furthermore, the practice drill aimed at teaching blocking (Blocking) was associated with a lower impact rate for all severity thresholds compared with tackling drills that involve players engaging with a blocker (Tackling-Blocker). In comparing the tackling drills, which only differed in whether a blocker was present to engage with the tackling defender (Blocker or No Blocker), we observed that a greater proportion of highermagnitude impacts was associated with the drill when a blocker was not present (Fig. 2). Reducing the time spent 
in drills of this nature can limit the frequency at which youth players are exposed to high-severity head impacts.

Both teams in the study spent about 3 -fold as much time conducting the Offense or Defense drill compared with the next most popular drill, Offense vs Defense (Table 2). The Offense or Defense drill resulted in a very low rate of impact and closely mimicked game play because it effectively served as an opportunity for the players to practice game plans and positioning. Offense vs Defense also exhibited fidelity to game situations, and the higher impact rate observed stems from the smaller number of players involved. With more open space in the field of play, players were able to achieve greater running speeds and thus produce higher-magnitude head impacts. The Offense or Defense drill allowed the teams to have 11 players on one side of the ball and work more on execution of plays. The Offense vs Defense drill opposed an offense and a defense with neither side having 11 players, with the goal being to simulate the physical side of the game. It should be noted that the small size of the teams (neither team exceeded 20 total players) prevented the teams from being able to conduct intrasquad scrimmages (11 players on each side of the ball), which would best represent a game situation.

Drills involving tackling were associated with impact rates similar to those for games, excluding King of the Circle (Fig. 1). However, tackling drills were associated with a greater proportion (between $40 \%$ and $50 \%$ ) of impacts exceeding $60 \mathrm{~g}$ than games (25\%). Even though most practice drills did not result in impact rates higher than those in games, practices led to a greater number of highmagnitude head impacts because there were more practices than games. The greater proportion of high-magnitude game impacts between $40 g$ and $60 g$ suggests that specific practice drills, primarily those that involve tackling, expose youth football players to more severe impacts than would be experienced in game play (Fig. 2).

Each practice session lasted 90 minutes, approximately 40 minutes of which were spent in non-football drill activities, such as running, stretching, instruction, and water breaks. On the season, $88 \%$ of the remaining 50 minutes was spent in one of the drills specified in Table 1, with the

\section{Avg. 90 min. Practice Observed}

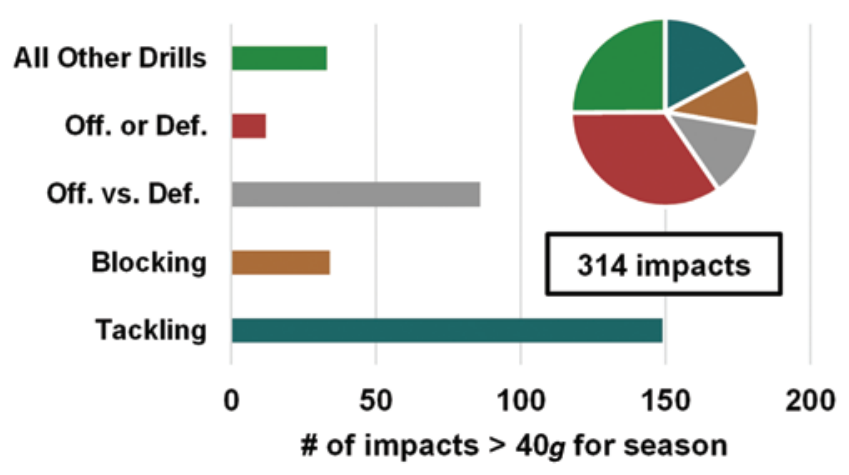

remaining $12 \%$ in drills that did not result in high-magnitude impacts. On average, this corresponded to 17 minutes spent in Offense or Defense, 9 minutes in tackling drills, 6 minutes in Offense vs Defense, 5 minutes in blocking drills, and the remaining 13 minutes in all other drills. The teams in this study participated in tackling or blocking drills for only $22 \%$ of their overall practice times, but these drills were responsible for $86 \%$ of all practice impacts exceeding $40 \mathrm{~g}$. If these 2 teams reduced the time spent in tackling or blocking drills by 5 minutes each practice, this would result in a $19 \%$ decrease in practice impacts over $40 \mathrm{~g}$. Similarly, a 10-minute reduction would result in a $38 \%$ decrease in such impacts (Fig. 3). A 50\% reduction in high-magnitude impacts would be observed in tackling and blocking drills with this reduction. To further reduce high-magnitude head impacts, the King of the Circle drill could be eliminated from youth practices because the very high impact rate was not representative of games.

Certain limitations of this study should be noted. The HIT System is associated with error up to $15.7 \%$ for individual acceleration measurements, although the mean overall error for many measurements is only $1 \% .{ }^{1}$ Individual acceleration measurements were used to determine impacts that exceeded the $40 \mathrm{~g}$ study threshold. Beyond that, the resulting analysis characterized distributions of data for which the effect of this error would be minimized. ${ }^{7}$ Other factors limit the applicability of these results to other situations. Just as the 2 teams studied here exhibited differences in head impact exposure and practice style, profiles of head impact exposure and practice structure likely will vary between teams and individuals. ${ }^{9-12}$ Head impact exposure and practice structure will vary by age group, ${ }^{3-5,7,11-14,27}$ and the game-to-practice ratio will vary by team and league.

\section{Conclusions}

Head impact kinematic data for 2 youth football teams of players 9-11 years old were collected to assess the effect of specific practice drills on impact exposure and their relation to game situations. For all impacts exceeding $40 \mathrm{~g}$, rates of impact for the most severe drills (those with the highest-magnitude impacts) do not differ from

\section{Modified $90 \mathrm{~min}$. Practice}

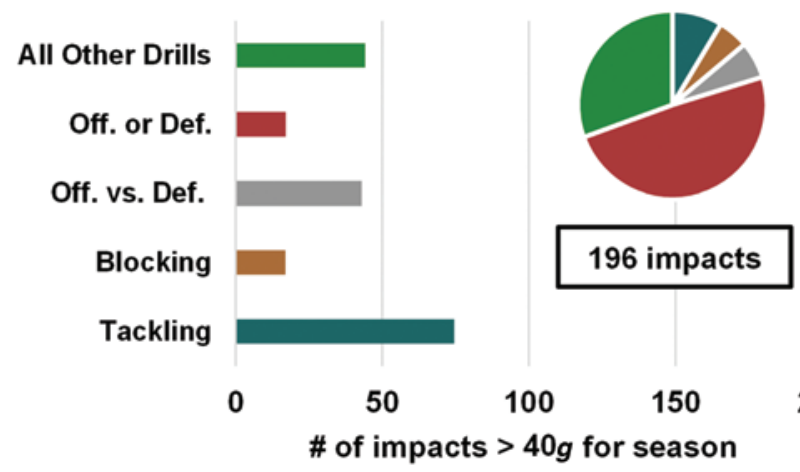

FIG. 3. In each 90-minute practice session, teams spent an average of 50 minutes practicing drills. A 10-minute reduction split between Tackling, Blocking, and Offense vs Defense drills would result in a $38 \%$ decrease in high-magnitude head impacts over the course of the season. The pie charts represent the proportion of the 50 minutes on average of practice time that were spent in each drill. Figure is available in color online only. 
those attained in games. At greater thresholds, up to $80 \mathrm{~g}$, tackling drills resulted in greater impact rates than games. These data suggest that a substantial reduction in highmagnitude head impacts in youth football could be attained through limiting the amount of contact in practice. Even though much practice time was spent in noncontact scenarios and several high-magnitude impacts recorded in this study occurred in noncontact situations, contact drills were associated with the majority of impacts over $40 \mathrm{~g}$. Coaches and league organizers can use these data to make informed decisions on practice structure that will help to reduce exposure to high-magnitude impacts. Further research into practice drill impact exposure at all levels of football is necessary to increase player safety and to characterize head impact exposure on a larger scale.

\section{Acknowledgments}

Research reported in this publication was supported by the National Institute of Neurological Disorders and Stroke of the National Institutes of Health under Award No. R01NS094410. The content is solely the responsibility of the authors and does not necessarily represent the official views of the National Institutes of Health. We gratefully acknowledge the Blacksburg Juniors football teams for their participation in this study.

\section{References}

1. Beckwith JG, Greenwald RM, Chu JJ: Measuring head kinematics in football: correlation between the head impact telemetry system and Hybrid III headform. Ann Biomed Eng 40:237-248, 2012

2. Breslow NE, Day NE: Statistical Methods in Cancer Research. Lyon: IARC Press, 1987, Vol 2

3. Broglio SP, Schnebel B, Sosnoff JJ, Shin S, Fend X, He X, et al: Biomechanical properties of concussions in high school football. Med Sci Sports Exerc 42:2064-2071, 2010

4. Broglio SP, Sosnoff JJ, Shin S, He X, Alcaraz C, Zimmerman J: Head impacts during high school football: a biomechanical assessment. J Athl Train 44:342-349, 2009

5. Broglio SP, Surma T, Ashton-Miller JA: High school and collegiate football athlete concussions: a biomechanical review. Ann Biomed Eng 40:37-46, 2012

6. Centers for Disease Control and Prevention: Nonfatal traumatic brain injuries related to sports and recreation activities among persons aged $\leq 19$ years-United States, 2001-2009. MMWR Morb Mortal Wkly Rep 60:1337-1342, 2011

7. Cobb BR, Urban JE, Davenport EM, Rowson S, Duma SM, Maldjian JA, et al: Head impact exposure in youth football: elementary school ages 9-12 years and the effect of practice structure. Ann Biomed Eng 41:2463-2473, 2013

8. Crisco JJ, Chu JJ, Greenwald RM: An algorithm for estimating acceleration magnitude and impact location using multiple nonorthogonal single-axis accelerometers. J Biomech Eng 126:849-854, 2004

9. Crisco JJ, Fiore R, Beckwith JG, Chu JJ, Brolinson PG, Duma S, et al: Frequency and location of head impact exposures in individual collegiate football players. J Athl Train 45:549-559, 2010

10. Crisco JJ, Greenwald RM: Let's get the head further out of the game: a proposal for reducing brain injuries in helmeted contact sports. Curr Sports Med Rep 10:7-9, 2011

11. Crisco JJ, Wilcox BJ, Beckwith JG, Chu JJ, Duhaime AC, Rowson S, et al: Head impact exposure in collegiate football players. J Biomech 44:2673-2678, 2011

12. Crisco JJ, Wilcox BJ, Machan JT, McAllister TW, Duhaime AC, Duma SM, et al: Magnitude of head impact exposures in individual collegiate football players. J Appl Biomech 28:174-183, 2012
13. Daniel RW, Rowson S, Duma SM: Head impact exposure in youth football. Ann Biomed Eng 40:976-981, 2012

14. Daniel RW, Rowson S, Duma SM: Head impact exposure in youth football: middle school ages 12-14 years. J Biomech Eng 136:094501, 2014

15. Duma SM, Rowson S: Past, present, and future of head injury research. Exerc Sport Sci Rev 39:2-3, 2011

16. Langlois JA, Rutland-Brown W, Wald MM: The epidemiology and impact of traumatic brain injury: a brief overview. J Head Trauma Rehabil 21:375-378, 2006

17. Manoogian S, McNeely D, Duma S, Brolinson G, Greenwald $\mathrm{R}$ : Head acceleration is less than 10 percent of helmet acceleration in football impacts. Biomed Sci Instrum 42:383388,2006

18. McGill R, Tukey JW, Larsen WA: Variations of box plots. Am Stat 32:12-16, 1978

19. Mihalik JP, Bell DR, Marshall SW, Guskiewicz KM: Measurement of head impacts in collegiate football players: an investigation of positional and event-type differences. Neurosurgery 61:1229-1235, 2007

20. Pellman EJ, Viano DC, Tucker AM, Casson IR, Waeckerle JF: Concussion in professional football: reconstruction of game impacts and injuries. Neurosurgery 53:799-814, 2003

21. Pop Warner National Office: Rule changes regarding practice \& concussion prevention. Pop Warner News. June 13, 2012. (http://www.popwarner.com/About_Us/Pop_Warner_News/ Rule_Changes_Regarding_Practice___Concussion_ Prevention_s1_p3977.htm) [Accessed May 17, 2016]

22. Rowson S, Brolinson G, Goforth M, Dietter D, Duma S: Linear and angular head acceleration measurements in collegiate football. J Biomech Eng 131:061016, 2009

23. Rowson S, Duma SM, Beckwith JG, Chu JJ, Greenwald RM, Crisco JJ, et al: Rotational head kinematics in football impacts: an injury risk function for concussion. Ann Biomed Eng 40:1-13, 2012

24. Schnebel B, Gwin JT, Anderson S, Gatlin R: In vivo study of head impacts in football: a comparison of National Collegiate Athletic Association Division I versus high school impacts. Neurosurgery 60:490-496, 2007

25. Stern RA, Riley DO, Daneshvar DH, Nowinski CJ, Cantu $\mathrm{RC}, \mathrm{McKee} \mathrm{AC}$ : Long-term consequences of repetitive brain trauma: chronic traumatic encephalopathy. PM R 3 (10 Suppl 2):S460-S467, 2011

26. Urban JE, Davenport EM, Golman AJ, Maldjian JA, Whitlow CT, Powers AK, et al: Head impact exposure in youth football: high school ages 14 to 18 years and cumulative impact analysis. Ann Biomed Eng 41:2474-2487, 2013

27. Young TJ, Daniel RW, Rowson S, Duma SM: Head impact exposure in youth football: elementary school ages 7-8 years and the effect of returning players. Clin J Sport Med 24:416-421, 2014

\section{Disclosures}

The authors report no conflict of interest concerning the materials or methods used in this study or the findings specified in this paper.

\section{Author Contributions}

Conception and design: Rowson, Duma. Acquisition of data: Campolettano. Analysis and interpretation of data: Campolettano. Drafting the article: Rowson, Campolettano. Critically revising the article: Rowson, Campolettano. Reviewed submitted version of manuscript: all authors. Study supervision: Duma.

\section{Correspondence}

Steven Rowson, Department of Biomedical Engineering and Mechanics, Virginia Tech, 343 Kelly Hall, 325 Stanger St., Blacksburg, VA 24061. email: srowson@vt.edu. 